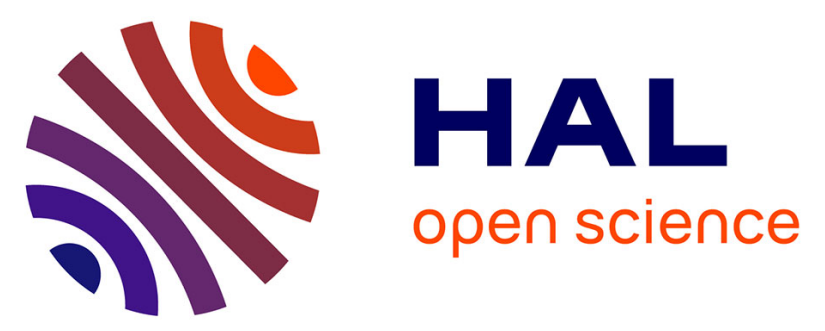

\title{
Design of Stimuli-Responsive Dynamic Covalent Delivery Systems for Volatile Compounds (Part 1): Controlled Hydrolysis of Micellar Amphiphilic Imines in Water
}

Eric Lutz, Emilie Moulin, Vera Tchakalova, Daniel Benczédi, Andreas Herrmann, Nicolas Giuseppone

\section{To cite this version:}

Eric Lutz, Emilie Moulin, Vera Tchakalova, Daniel Benczédi, Andreas Herrmann, et al.. Design of Stimuli-Responsive Dynamic Covalent Delivery Systems for Volatile Compounds (Part 1): Controlled Hydrolysis of Micellar Amphiphilic Imines in Water. Chemistry - A European Journal, 2021, 27 (53), pp.13457-13467. 10.1002/chem.202102049 . hal-03419105

\section{HAL Id: hal-03419105 https://hal.science/hal-03419105}

Submitted on 8 Nov 2021

HAL is a multi-disciplinary open access archive for the deposit and dissemination of scientific research documents, whether they are published or not. The documents may come from teaching and research institutions in France or abroad, or from public or private research centers.
L'archive ouverte pluridisciplinaire HAL, est destinée au dépôt et à la diffusion de documents scientifiques de niveau recherche, publiés ou non, émanant des établissements d'enseignement et de recherche français ou étrangers, des laboratoires publics ou privés. 


\title{
Design of Stimuli-Responsive Dynamic Covalent Delivery Systems for Volatile Compounds (Part 1): Controlled Hydrolysis of Micellar Amphiphilic Imines in Water
}

\author{
Eric Lutz, ${ }^{[a]}$ Emilie Moulin, ${ }^{[a]}$ Vera Tchakalova, ${ }^{[b]}$ Daniel Benczédi, ${ }^{[b]}$ Andreas Herrmann, ${ }^{[b] \star}$ and Nicolas \\ Giuseppone $e^{[\mathrm{a}] *}$
}

Dedicated to the memory of Prof. François Diederich

\begin{abstract}
Despite their intrinsic hydrolysable character, imine bonds can become remarkably stable in water when self-assembled in amphiphilic micellar structures. In the present article, we systematically study some of these structures and the influence of various parameters that can be used to take control over their hydrolysis, including $\mathrm{pH}$, concentration, position of the imine function in the amphiphilic structure, relative lengths of the linked hydrophilic and hydrophobic moieties. Thermodynamic and kinetic data lead us to the rational design of stable imines in water, partly based on the location of the imine function within the hydrophobic part of the amphiphile and on a predictable quantitative term that we define as the total hydrophilic-lipophilic balance (HLB). In addition, we show that such stable systems are also stimuli-responsive and therefore, of potential interest in trapping and releasing micellar components on demand.
\end{abstract}

\section{Introduction}

Dynamic covalent chemistry extends the general principle of "reversible binding" that is at the foundation of supramolecular chemistry. It makes use of reversible covalent bonds to build associative-dissociative molecular systems in which the equilibrium position can be precisely shifted, depending on various internal and external parameters. ${ }^{[1-7]}$ Over the past 15 years, this approach has been successfully implemented in the design of dynamic receptors, ${ }^{[8,9]}$ substrates and inhibitors, ${ }^{[10,11]}$ catalysts, ${ }^{[12,13]}$ and stimuli-responsive materials. ${ }^{[14-28]}$ Furthermore the set-up of so-called dynamic mixtures by reversible covalent bond formation of multicomponent systems has been used to

[a] Dr. E. Lutz, Dr. E. Moulin, Pr. Dr. N. Giuseppone SAMS research group Institut Charles Sadron, CNRS,

University of Strasbourg, 23 rue du Loess, BP 84047 ,

F-67034 Strasbourg Cedex 2, France.

E-mail: giuseppone@unistra.fr, ORCID: 0000-0003-4093-3000

[b] Dr. V. Tchakalova, Dr. D. Benczédi, Dr. A. Herrmann

Firmenich SA, Corporate R\&D Division

Rue de la Bergère 7

$\mathrm{CH}-1242$ Satigny, Switzerland

E-mail: andreas.herrmann@firmenich.com, ORCID: 0000-00016997-3458

Supporting information for this article is given via a link at the end of the document. control the sensing, transport and release of volatile compounds. ${ }^{[29]}$ For practical implementation, dynamic covalent bonds usually need to combine fast equilibration times together with sufficient thermodynamic stabilities. ${ }^{[30,31]}$ Among the efficient systems described in the literature, one can find examples based on the exchange of disulphides ${ }^{[32]}$ and thioesters; ${ }^{[33,34]}$ on DielsAlder $^{[35]}$ and nitroaldo| ${ }^{[36]}$ reactions; on dynamic native chemical ligation; ${ }^{[37]}$ and on acetal, ${ }^{[38]}$ aminal, ${ }^{[39,40]}$ boronic esters, ${ }^{[41,42]}$ and imine (Schiff base) condensations. ${ }^{[19,43,44]}$ In the present article, we take a closer look at the possibility of increasing imine bond stability in water by taking advantage of surfactant micellization. Indeed, the hydrolysable character of imines is by essence detrimental to their condensation in water according to Le Chatelier's principle. Although parameters such as concentration, stoichiometry, $\mathrm{pH}$ and temperature can contribute to shifting the equilibrium towards condensation, full hydrolysis is often observed in various experimental contexts of interest requiring diluted aqueous solutions. ${ }^{[24,43,45]}$ Recently, we and others observed the possibility of influencing the equilibrium and kinetic constants of imine formation when imines are partially protected from water in amphiphilic micellar structures. ${ }^{[46-49]}$ In particular, it has been shown that the use of imine-based surfactants can lead to $(I)$ their autocatalytic condensation in a process related to autopoiesis ${ }^{[4-50]}$ and to (ii) their modular and controllable recombination in various types of dynamic micellar and vesicular structures. ${ }^{[51-58]}$

Among a number of industrially relevant applications, amphiphilic structures are commonly used to solubilize hydrophobic volatile compounds, such as fragrances, in aqueous formulations of almost all perfumed body care or household products. Cleavable surfactants with a labile chemical bond, typically located between the hydrophilic and hydrophobic section of the amphiphile, have been proposed in order to increase the biodegradability of these products. ${ }^{[59-61]}$ The cleavable bond needs to be sufficiently stable during storage of the formulation to ensure the performance of the surfactant in application, but labile enough to decompose after use. From our previous experience with micellar imines, we wondered whether a profragrance ${ }^{[62-64]}$ could be generated by reversible condensation of a hydrophobic fragrance aldehyde with a hydrophilic amine compound. Imine-based cleavable surfactants would also be potentially useful to solubilize other volatile perfumery compounds in an aqueous environment and would hydrolyse as a response to dilution and/or a change of $\mathrm{pH}$ to release the fragrance aldehyde by disintegration of the amphiphile. 
As a first approach, we decided to study the parameters that stabilize - or destabilize - non-ionic amphiphilic imines in water, the aim being to design stimuli-responsive surfactants that would be able to encapsulate and release hydrophobic molecules on demand and over a given period of time. The coupled equilibria involved (molecular and supramolecular) are schematically represented in Figure 1.

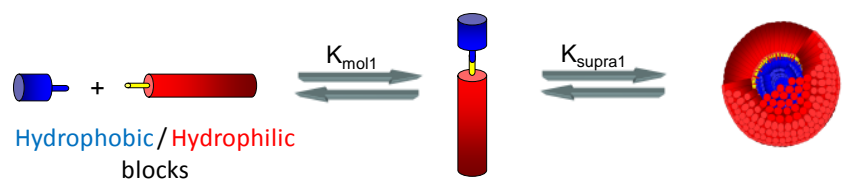

Figure 1. Generic representation of the condensation of hydrophobic aldehydes (blue) with hydrophilic amines (red) in water, yielding amphiphilic imines. Depending on various parameters, amphiphilic imines can subsequently self-assemble in micellar structures. Such supramolecular structures can affect the stability of the imine bond by protecting it from water when integrated in the hydrophobic micellar core. ${ }^{[49]}$

In the present paper, we discuss the thermodynamic and kinetic influence of various parameters on such systems, including $\mathrm{pH}$, concentration, chemical nature of the imine and position of the imine in the amphiphilic structure, as well as the relative lengths of the linked hydrophilic and hydrophobic moieties. As a main result, we demonstrate that the location of the imine function within the hydrophobic part of the amphiphile and its total hydrophilic-lipophilic balance (HLB) are key parameters for the performance of these systems as surfactants. In a second study described in a separate article, we implement this fundamental knowledge and demonstrate the controlled release of fragrances in the context of a realistic application. ${ }^{[65-69]}$

\section{Results and Discussion}

\section{Rational design and chemical structures of amphiphilic imine derivatives}

The various chemical structures used in this study reflect two complementary objectives. The first objective is to rationalize the stability of imine-based surfactants in water, depending on structural parameters such as $(I)$ the type of imine bond involved (e.g. aliphatic, aromatic), (ii) the respective lengths of the hydrophobic and hydrophilic parts within the surfactant and (iii) the resulting overall HLB of the amphiphile to form a cleavable surfactant. The second objective is to use such potentially stimuliresponsive amphiphiles for the controlled release of volatiles (fragrances) in a real application context. This aspect requires cheap starting materials, simple chemical derivations, and products with low toxicity. It also invites us to potentially integrate hydrophobic fragrances directly within the amphiphilic imine structure (e.g. in the form of hydrophobic volatile aldehydes) to form a profragrance. A series of imine-based profragrances that form liquid crystals, polymers or gels has been reported in the literature, ${ }^{[20,65-69]}$ one study also investigating some properties of micellar polymer aggregates. ${ }^{[58]}$
From the present set of constraints and opportunities, we decided to include in our study a series of six aldehyde derivatives $(\mathbf{A}-\mathbf{F})$. Two of them ( $\mathbf{A}$ and $\mathbf{B}$ ) allowed us to investigate fundamental aspects of the stability of the micelles; the other four $(\mathbf{C}-\mathbf{F})$ were typical fragrance aldehydes, namely hexylcinnamic aldehyde (C), citral (D) and (Z)-4-dodecenal (E) as aliphatic and hydrophobic aldehydes and vanillin (F) as an aromatic and more hydrophilic aldehyde (Figure 2a).

a)

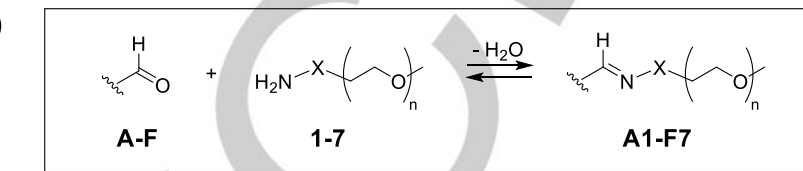

A<smiles>CCCCCCCc1ccc(C=O)c(/C=C/c2ccc(NC(=O)NCCCCC)cc2)c1</smiles>

E<smiles>COc1cc(C=O)ccc1O</smiles>

b)
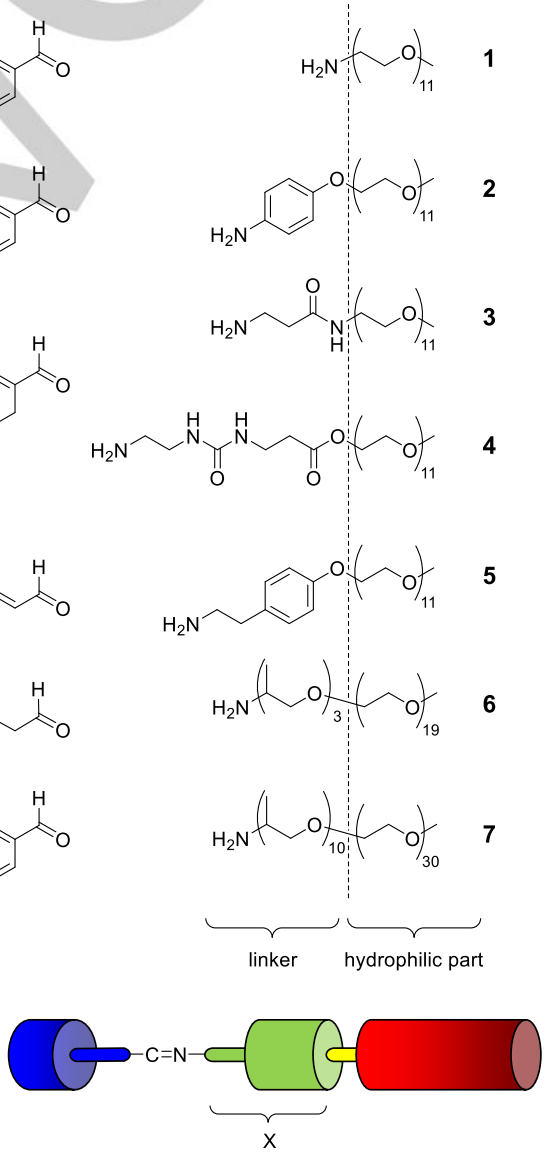

c)

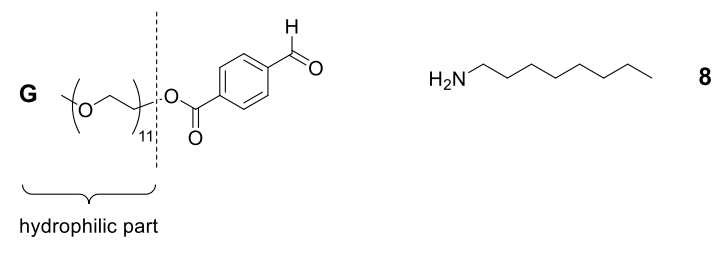

Figure 2. a) Reversible condensation of aldehydes (A-F) with hydrophilic amines (1-7) to form imine-based cleavable surfactants (A1-F7). b) General structure of the condensed imines showing three domains within the surfactant: a hydrophobic domain (blue), a linker ( $X$, green) placing the imine bond in a hydrophobic environment, and a hydrophilic domain (red). c) Structures of hydrophilic aldehyde $\mathbf{G}$ and hydrophobic amine $\mathbf{8}$ to form imine $\mathbf{G} \mathbf{8}$ with inversed polarity compared with that in A1-F7. 
As they are hydrophilic amines, we selected a series of poly(ethylene glycol) (PEG)-derived structures without a linker (1) or with variable lengths of a linker $(X)$ between the amine and the PEG units (2-7) to generate a more or less hydrophobic environment in proximity to the imine bond to be formed (Figure 2a). The different amines were derived from aniline (2), glycinamide (3), carbamate urea (4), or tyramine (5). In addition, we tested two commercially available derivatives of the Jeffamine ${ }^{\circledR}$ family, which are diblock copolymers composed of a poly(propylene oxide) and poly(ethylene oxide) unit of variable lengths, namely M1000 (6) and M2070 (7).

When condensed to imines, the generic surfactants that are produced present three domains that play an important role in imine stabilization (Figure 2b). In addition to the hydrophobic and hydrophilic moieties, we will highlight the strong influence of the relative hydrophobicity of the (small) group of atoms immediately linking the primary amine with the hydrophilic tail, denoted as linker $(\mathrm{X})$ in Figure 2a/b. Finally, as an additional example, we investigated the combination of a hydrophilic PEG-derived aldehyde (G) with hydrophilic octylamine (8) to form an imine with "inversed" polarity compared with that in A1-F7 (Figure 2c).

The synthetic protocols and characterizations of all products presented in Figure 2 are detailed in the Supporting Information (SI).

\section{General stability rules of amphiphilic imines in water}

The kinetics of hydrolysis and thermodynamic stability of the imine derivatives presented in Figure 2 were determined as follows. Fully condensed imines, initially prepared in organic solvents (see $\mathrm{SI})$, were dissolved at a typical concentration $(\mathrm{c}=10 \mathrm{mM})$ in deuterium oxide $(\approx 1 \% \mathrm{w} / \mathrm{w})$, and the $\mathrm{pD}$ was immediately measured $\left(\mathrm{pD}=\mathrm{pH}_{\text {measured }}+0.4\right){ }^{[24,70]}$ The hydrolysis was then followed by integrating the imine $(8 \mathrm{ppm})$ and the aldehyde $(9.5$ $10.0 \mathrm{ppm})$ resonance signals $\left(I_{\text {imine }}(t)\right.$ and $I_{\text {aldehyde }}(t)$, respectively) in the corresponding ${ }^{1} \mathrm{H}$ NMR spectra and by plotting the imine concentration as a function of time following equation (1):

$$
C_{\text {imine }(t)}=C_{0} * \frac{I_{\text {imine }}(t)}{I_{\text {aldehyde }}(t)+I_{\text {imine }}(t)}
$$

A typical concentration profile (illustrated here with imine A2) is shown in Figure 3a. From this plot, one can determine the amount of condensed product at equilibrium $\left(\mathrm{C}_{\mathrm{eq}}=2.5 \mathrm{mM}\right)$ and the initial rate of hydrolysis $\left(\mathrm{V}_{0}=9 \times 10^{-3} \mathrm{mM} \mathrm{min}^{-1}\right)$. One can also notice a linear decrease of imine $\mathbf{A} 2$ during the first $6 \mathrm{~h}$, which cannot be fitted by a second-order kinetic plot and which highlights the complex kinetics of hydrolysis associated with the formation of spherical micelles of $7 \mathrm{~nm}$ diameter for this particular surfactant. ${ }^{[46]}$ Hence, in such "nanostructured reservoirs", the imine bond is, to a certain extent, protected from water molecules within the micellar hydrophobic core. Obviously, depending on the critical micellar concentration (CMC), various amounts of unimers (i.e. single surfactant imines) are also solubilized in water and can be easily hydrolysed. In addition, when considering the tendency of the released hydrophobic aldehyde to in turn be solubilized in the micellar core, the overall kinetics becomes even more complex. One can, however, determine a pseudo-first-order constant of hydrolysis $\left(\mathrm{k}_{\mathrm{h}}=\mathrm{V}_{0} / \mathrm{C}_{0}=0.9 \times 10^{-3} \mathrm{~min}^{-1}\right)$, reflecting the kinetics that the system would have if it was not stabilized by the micellar structure.
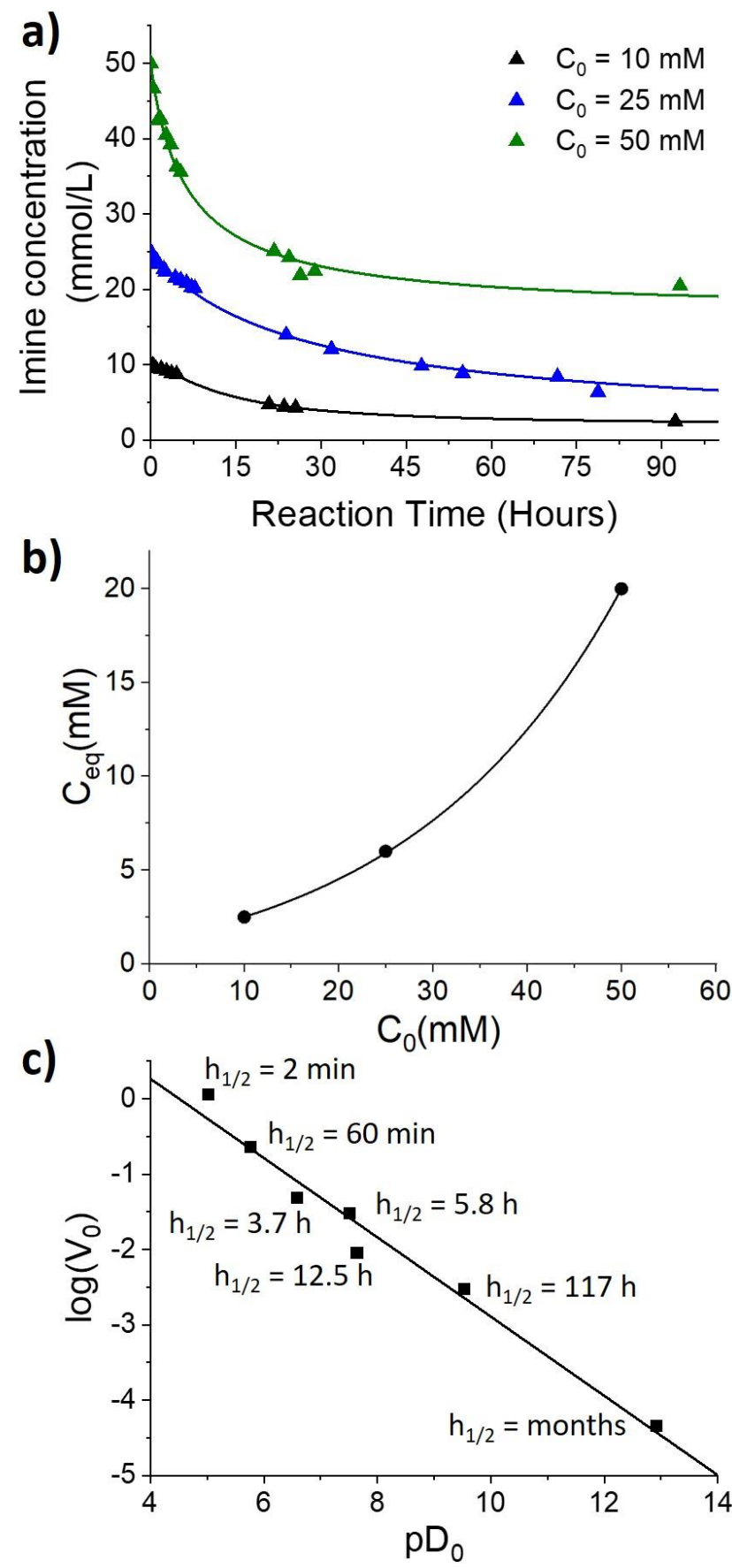

Figure 3. a) Plot of the hydrolysis profile of imine $\mathbf{A} 2$ as a function of time for different initial concentrations $\mathrm{C}_{0}$. b) Influence of $\mathrm{C}_{0}$ on the concentration at thermodynamic equilibrium $\mathrm{C}_{\text {eq. }}$ c) Influence of $\mathrm{pD}$ on the half-time of hydrolysis $\left(h_{1 / 2}\right)$ starting from a solution of imine $\mathbf{A} 2$ at $C_{0}=10 \mathrm{mM}$. 
We then assessed the influence of the total concentration on the thermodynamic and kinetic parameters for the same reference imine (A2). We measured the hydrolysis profile for three concentrations of starting material $(10,25$ and $50 \mathrm{mM})$, with an initial $\mathrm{pD}$ varying between 7.4 and 8.3 , and we determined the corresponding $\mathrm{V}_{0}, \mathrm{k}_{\mathrm{h}}$ and $\mathrm{C}_{\text {eq }}$ values (see Figure $3 \mathrm{a}$ and Table 1 ). Not surprisingly, reducing the initial imine concentration slowed the hydrolysis and decreased the amount of imine present at thermodynamic equilibrium (Figure $3 b$ ). This is of interest for the intended use as delivery systems where, during the final application formulation, relatively small concentrations of the system are typically encountered, e.g. after dilution.

Finally, we measured the influence of the $\mathrm{pD}$ on the rate of hydrolysis - which is well known to be acid catalysed[71] - by modifying at the initial time the acidity of the solution with a controlled addition of $\mathrm{NaOD}$ or $\mathrm{CF}_{3} \mathrm{CO}_{2} \mathrm{D}$. The corresponding halflife times of hydrolysis $\left(h_{1 / 2}\right)$ (which are necessary to reach a concentration of $5 \mathrm{mM}$ in imine) are shown as a function of $\mathrm{pD}$ values (between 5 and 13) in Figure 3c. Interestingly, a very large range of characteristic half-life times was observed, with values being between $2 \mathrm{~min}($ at $\mathrm{pD}=5.0$ ) and several months (at $\mathrm{pD}=$ 13.0). Figure $3 \mathrm{c}$ illustrates the impact of the $\mathrm{pH}$ to generate stimuli-responsive micellar systems that can be either highly stable or rapidly dissociate on demand. This is also relevant for practical uses of the system because structural modifications might allow adjustment of the rates of hydrolysis to a specific time window.

Table 1: Thermodynamic and kinetic values determined for the hydrolysis of imine $\mathbf{A} 2$ in deuterated water.

\begin{tabular}{cccc}
\hline $\mathrm{C}_{0}$ imine $(\mathrm{mM})$ & $\mathrm{V}_{0}\left(10^{-3} \mathrm{mM} \mathrm{mn}^{-1}\right)$ & $\begin{array}{c}\mathrm{kh}_{\mathrm{h}}\left(10^{-3} \mathrm{~min}^{-1}\right) \\
{\left[\mathrm{h}_{1 / 2}(\mathrm{~h})\right]}\end{array}$ & $\mathrm{C}_{\text {eq }}(\mathrm{mM})$ \\
\hline 10 & 9.0 & $0.9[12.5]$ & 2.5 \\
25 & 40.9 & $1.64[14]$ & 6.0 \\
50 & 126.3 & $2.53[16]$ & 20.0 \\
\hline
\end{tabular}

We then measured the size of the micelles during the course of hydrolysis of imine $\mathbf{A 2}$. The hydrodynamic radii $\left(R_{h}\right)$ of the micelles measured by dynamic light scattering (DLS) are illustrated in Figure 4 as a function of hydrolysis time until the size of the micelles was found to be stable (after around $400 \mathrm{~min}$ ).

The large polydispersity observed by DLS (Figure 4a), ranging from half to twice the average micellar size, is here partly due to the polydispersity of the $P E G_{11} \mathrm{OH}$ chain used in the synthesis (between $P E G_{6} \mathrm{OH}$ and $\mathrm{PEG}_{16} \mathrm{OH}$ as determined by ESI-MS). Figure $4 \mathrm{~b}$ shows a linear increase of $R_{h}$ as a function of hydrolysis time, moving from $6.5 \mathrm{~nm}$ to $13.8 \mathrm{~nm}$ after $6 \mathrm{~h}$, which represents a speed of $0.02 \mathrm{~nm} \mathrm{~min}{ }^{-1}$. At this moment, the concentration of imine is $5 \mathrm{mM}$, and the increase in size corresponds to the entrapment of the released hydrophobic aldehyde in the remaining micellar imine structures, as described in our previous studies. ${ }^{[46,48,49]}$ In addition, after $3 \mathrm{~h}$, another population of larger objects $\left(R_{h}>100 \mathrm{~nm}\right)$ appeared with a rapidly increasing size of $0.65 \mathrm{~nm} \mathrm{~min}^{-1}$, and this microemulsion continued to grow after the disappearance of the small micelle population, leading to a turbid solution and eventually to a macroscopic phase separation (Figure 4c).
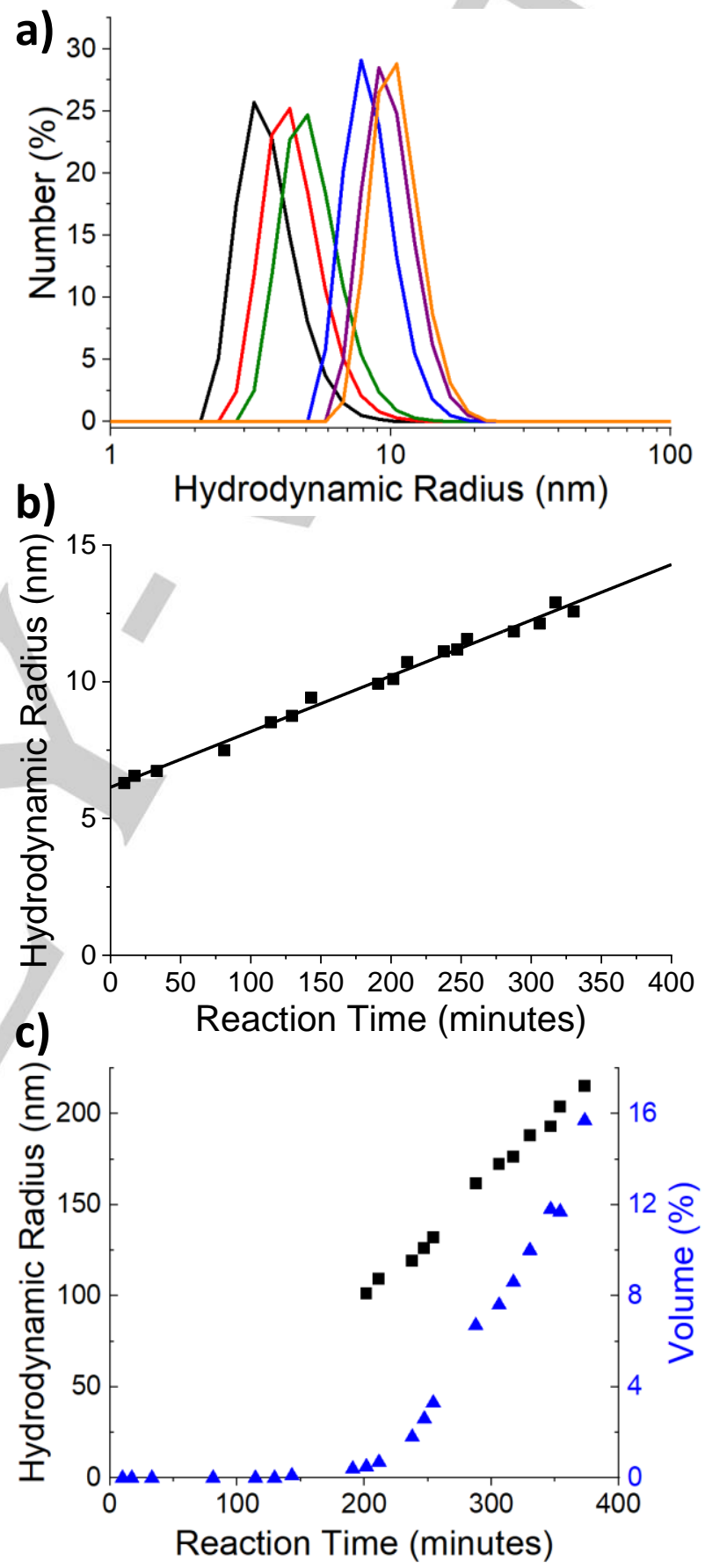

Figure 4. a) DLS measurements of the hydrodynamic radius $\left(R_{h}\right)$ of micelles of imine $\mathbf{A} 2$ during hydrolysis $\left(\mathrm{C}_{0}=10 \mathrm{mM} ; \mathrm{pD}_{0}=8.0\right)$. Hydrolysis time: $10 \mathrm{~min}$ (black), $80 \mathrm{~min}$ (red), $143 \mathrm{~min}$ (green), $247 \mathrm{~min}$ (blue), $317 \mathrm{~min}$ (purple), 373 min (orange). b) Evolution of the micellar $R_{h}$ as a function of hydrolysis time for imine A2. c) Evolution of the hydrodynamic radius (black) and volume percentage (blue) of an emulsion of aldehyde $\mathbf{A}$ as a function of time monitored by DLS (A2 in $\left.\mathrm{D}_{2} \mathrm{O}, \mathrm{C}_{0}=10 \mathrm{mM}\right)$. 
From these preliminary results using our reference imine $\mathbf{A 2}$, we tried to explore the possibility of stabilizing the micellar structure by introducing hydrogen bonding units into the imine surfactants. We therefore investigated the hydrolytic behaviour of imine B2, which contains a urea function in the hydrophobic part of its structure (Figure $\mathrm{S} 1$ ). Surprisingly, at $\mathrm{C}_{0}=10 \mathrm{mM}$ and $\mathrm{pD}=8.9$, we measured an initial rate of hydrolysis of $V_{0}=17 \mathrm{mM} \mathrm{min}^{-1}, \mathrm{~h}_{1 / 2}$ $=5 \mathrm{~h}$, and complete hydrolysis after $8 \mathrm{~h}$. This increased propensity to hydrolyse might be attributed to the polarity of the urea group, which attracts water molecules in their vicinity, but also to the stronger tendency of aldehyde $\mathbf{B}$ to phase separate as compared with octyl benzaldehyde (A). Indeed, aldehyde B is a solid, which was hardly soluble in water, and a white precipitate was observed in the course of the hydrolysis of imine $\mathbf{B 2}$.

We then studied the influence of the chemical structure of the hydrophilic amine on the hydrolysis rate (Figure S2). We first compared the behaviour of the reference aromatic amine 2 leading to A2 with that of its corresponding aliphatic analogue 1 leading to $\mathbf{A} 1$. At $\mathrm{C}_{0}=10 \mathrm{mM}$ and $\mathrm{pD}=10.2$, the characteristic hydrolysis time $\mathrm{h}_{1 / 2}$ was $3.5 \mathrm{~h}$ (compared with $120 \mathrm{~h}$ for imine $\mathbf{A 2}$ at a similar $\mathrm{pD}$ ), and full hydrolysis was reached after $24 \mathrm{~h}$. Despite the higher nucleophilicity of aliphatic amines compared with that of aniline, we attributed the observed higher sensitivity of $\mathbf{A} 1$ towards hydrolysis with respect to $\mathbf{A} 2$ to the direct linkage of the primary amine to the hydrophilic PEG chain in the case of A1, which increased the effective concentration of water at the immediate vicinity of the imine bond within the micellar structure. Attempts to stabilize the micellar structure by adding hydrogen bonding units in the form of amide functions into the hydrophilic part of the surfactant (as in imine A3) were unsuccessful (Figure S3). With $\mathrm{h}_{1 / 2}=1 \mathrm{~h}$ at $\mathrm{pD}=8.3$ (12 times faster than reference $\mathbf{A 2}$ ), and complete hydrolysis after $4 \mathrm{~h}$, the hydrogen bonds again appeared to destabilize the system. By following the size of the micelles by DLS, we observed two coexisting populations from the beginning of the hydrolysis, a smaller one $\left(R_{h 1}=3.8 \mathrm{~nm}\right)$ and a larger one $\left(R_{h 2}=100 \mathrm{~nm}\right)$. Both increased in size during the course of the reaction (up to $R_{h 1}=50 \mathrm{~nm}$ and $R_{h 2}=400 \mathrm{~nm}$ ) until micellar aggregates were no longer observed due to macroscopic phase separation (Figure S4). A similar behaviour of enhanced hydrolysis was found for imine A4, containing both a carbamate unit and a urea group attached to the primary amine (Figure S5). Again, these examples illustrated (as observed when we attempted to stabilize the micelles by adding hydrogen bonding units in the hydrophobic part) that macroscopic phase separation is a strong driving force that pushes the equilibrium towards hydrolysis by removing one product from solution and should carefully be taken into account when designing these types of dynamic amphiphiles.

We then turned to another strategy to stabilize the imine surfactants in water by introducing a hydrophobic linker between the amine and the hydrophilic tail, as in imine G8. Compared with A1, the aromatic aldehyde was switched from a hydrophobic to a hydrophilic moiety and, conversely, the aliphatic amine was switched from a hydrophilic to a hydrophobic moiety. The hydrolysis of G8 was performed at various $\mathrm{pD}$ values and concentrations (Figure 5). Interestingly, imine G8 was found to be particularly stable against hydrolysis, although it appeared to be particularly $\mathrm{pH}$ sensitive as well. Table 2 illustrates these variable characteristics when compared with those of imine A1. Figure 5 and Table 2 together provide useful information on several important factors that can be used to stabilize amphiphilic imines in water. Imine G8 showed a high hydrolysis dependency on pD, with four different domains: (a) for $\mathrm{pD}<7.4$, complete hydrolysis was observed in less than $1 \mathrm{~h}$; (b) for $7.4<\mathrm{pD}<9.9$, a very fast initial hydrolysis was followed by a very slow hydrolysis until near completion; (c) for $9.9<\mathrm{pD}<11.4$, a very slow hydrolysis was observed from the beginning until near complete hydrolysis; (d) for $\mathrm{pH}>11.4$, hydrolysis proceeded at a moderate rate until completion due to the cleavage of the ester bond. It was interesting to observe that by changing the initial $\mathrm{pD}$ value by 2 units (from 8.2 to 10.2), the half-life time of hydrolysis extended by a factor of 500 (i.e. from $30 \mathrm{~min}$ to 10 days).

Table 2: Comparison of hydrolysis characteristics $\left(\mathrm{h}_{1 / 2}\right.$ and $\left.\mathrm{C}_{\mathrm{eq}}\right)$ for imines $\mathbf{A} 1$ and $\mathbf{G 8}$ in deuterated water starting from an initial concentration of $\mathrm{C}_{0}=10 \mathrm{mM}$ and depending on $\mathrm{pD}$.

\begin{tabular}{cccc}
\hline Imine $(\mathrm{mM})$ & $\mathrm{pD}$ & $\mathrm{h}_{1 / 2}(\mathrm{~h})$ & $\mathrm{C}_{\text {eq }}(\mathrm{mM})$ \\
\hline $\mathbf{A 1}(10 \mathrm{mM})$ & 7.9 & 5.8 & 2.5 \\
$\mathbf{A} 1(10 \mathrm{mM})$ & 8.0 & 12.5 & 2.6 \\
$\mathbf{A} 1(10 \mathrm{mM})$ & 9.9 & 117 & 2.8 \\
G8 $(10 \mathrm{mM})$ & 8.2 & 0.5 & 0 \\
G8 $(25 \mathrm{mM})$ & 8.2 & 151 & 21.8 \\
$\mathbf{G} 8(10 \mathrm{mM})$ & 8.8 & 78 & 4.5 \\
G8 $(10 \mathrm{mM})$ & 10.2 & 242 & 6.5 \\
\hline
\end{tabular}

This obviously correlated well with the pKa of the aliphatic amine (around 10.6) and agrees with the higher stability of imine A1 at low $\mathrm{pH}$, corresponding to a lower $\mathrm{pKa}$ of the aniline structure (around 4.5). This also shows that imines involving aliphatic amines can be very stable if not placed in a medium below their $\mathrm{pKa}$. Finally, the effect of the ester hydrolysis at $\mathrm{pD}>11.4$ showed that fast hydrolysis is reached for a similar function and $\mathrm{pD}$ if the imine loses its amphiphilic character, thus further confirming the importance of the micellization in imine condensation. However, as shown by the experiments performed with $\mathbf{G} 8$ at $\mathrm{pD}=8.2$ but for $\mathrm{C}_{0}=25 \mathrm{mM}, \mathrm{C}_{\text {eq }}$ showed a high level of condensation, which was not necessarily expected from what was observed at $C_{0}=10$ $\mathrm{mM}$, and at least demonstrated the non-linearity of the condensation process. However, this result was not too surprising with respect to the interplay between the coupled molecular and supramolecular equilibria (Figure 1). In such systems, the variation of the free Gibbs energy for the imine condensation is superimposed with a phase diagram that expresses various ratios between free imine and micellar imines depending on the total concentration. In other words, when crossing the phase diagram from unimers to micelles, there is a concomitant non-linear shift of the imine bond towards condensation. These strong effects on $\mathrm{C}_{\text {eq }}$ can also be found when changing the concentration of octylamine by hydrolysing imine $\mathbf{G 8}(10 \mathrm{mM})$ in the presence of 
$10 \mathrm{mM}$ of octylamine (Figure S6). We observed that at a pD of 9.2, G8 rapidly stabilized at $C_{\text {eq }}=9.1 \mathrm{mM}$ instead of $4.5 \mathrm{mM}$ without extra amine. This change can be evaluated by an apparent stability constant, with $\mathrm{K}_{\mathrm{app}}=14 \mathrm{M}^{-1}$ at $\mathrm{C}_{\text {amineT }}=10 \mathrm{mM}$ and $\mathrm{a}$ much higher $\mathrm{K}_{\mathrm{app}}=92 \mathrm{M}^{-1}$ at $\mathrm{C}_{\mathrm{amineT}}=20 \mathrm{mM}$.
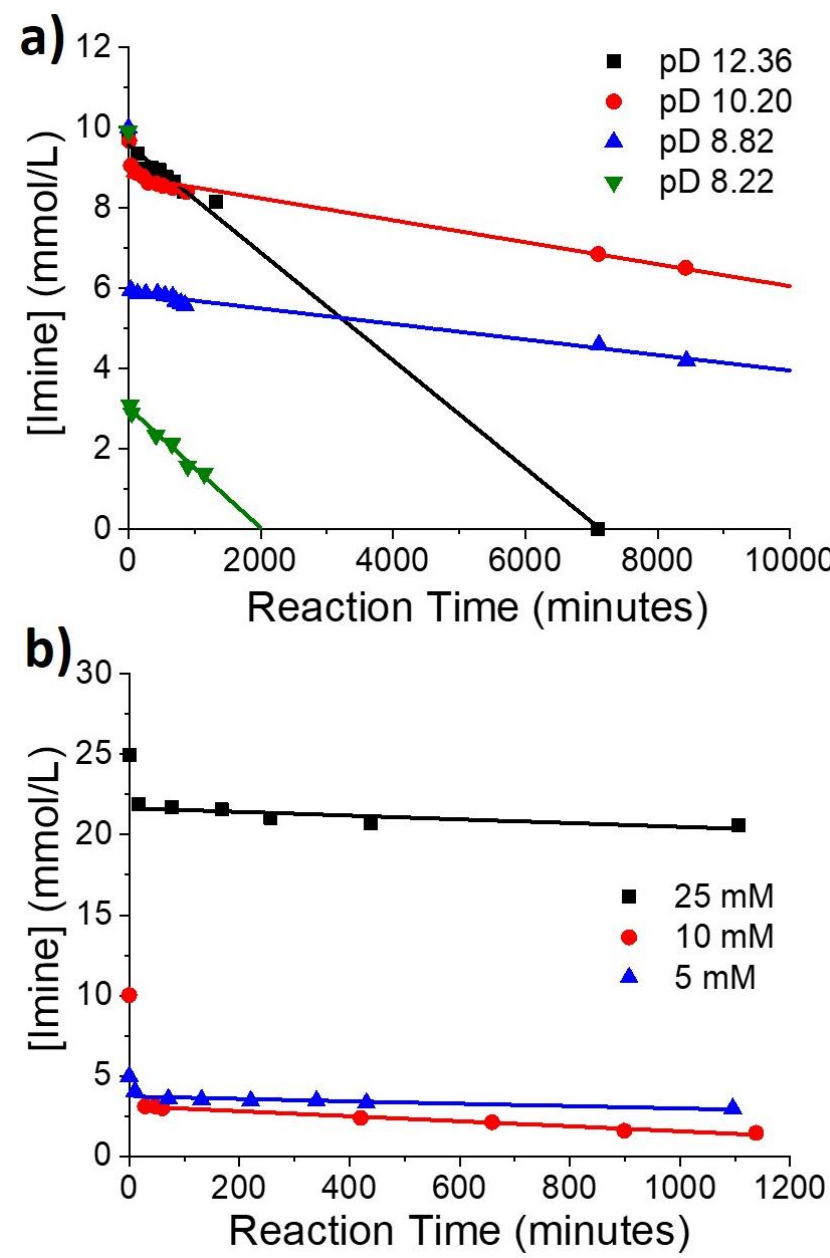

Figure 5. a) Evolution of the concentration of imine $\mathbf{G 8}$ as a function of time in $\mathrm{D}_{2} \mathrm{O}$ at different $\mathrm{pDs}\left(\mathrm{C}_{0}=10 \mathrm{mM}\right.$, unmodified $\left.\mathrm{pD}_{0}=10.2\right)$. b) Evolution of the concentration of imine $\mathrm{G} 8$ as a function of time in $\mathrm{D}_{2} \mathrm{O}$ for different initial concentrations and at $\mathrm{pD}_{0}=8.3\left(\mathrm{C}_{0}=5\right.$ (blue), 10 (green) and 25 (red) $\mathrm{mM}$ ).

\section{Design of a micellar imine-based profragrance and its controlled release}

We then investigated the possibility of controlling the condensation and hydrolysis of hydrophobic fragrance aldehydes (e.g. hexylcinnamic aldehyde (C)) with a series of hydrophilic amines in water. For making the profragrances, we selected aliphatic amines that are less problematic for the targeted applications - from a toxicity point of view - than aromatic amines. From what we learned earlier, we selected primary amines with a hydrophobic linker between the amine group and the hydrophilic PEG tail. For our tests, we selected $\mathrm{PEG}_{11}$ tyramine 5, as well as poly(propylene oxide) and poly(ethylene oxide) diblock copolymer amines 6 and 7, which are commercially available as Jeffamines ${ }^{\circledR}$ M1000 (6) and M2070 (7). As a reference, we also used amine 1 with no hydrophobic linker group between the amine and the hydrophilic PEG group.

Starting with hexylcinnamic aldehyde $(\mathbf{C})$, we compared the rates of hydrolysis of imines $\mathbf{C 1}, \mathbf{C 5}$ and $\mathbf{C 6}$ at $\mathrm{C}_{0}=10 \mathrm{mM}$ and $10.1<$ $\mathrm{pD}<10.5$ (see Table 3 and Figure S7).

Table 3: Kinetic and thermodynamic values determined for the hydrolysis of imine $\mathbf{C 1}, \mathbf{C 5}$ and $\mathbf{C 6}$ in deuterated water.

\begin{tabular}{cccc}
\hline Imine $\left(\mathrm{C}_{0}=10 \mathrm{mM}\right)$ & $\mathrm{pD}$ & $\mathrm{V}_{0}\left(10^{-3} \mathrm{mM}_{\mathrm{mn}}^{-1}\right)$ & $\mathrm{h}_{1 / 2}(\mathrm{~h})$ \\
\hline C1 & 10.5 & 14.8 & 4.5 \\
C5 & 10.1 & 1.3 & 150 \\
C6 & 10.5 & 6.8 & 12
\end{tabular}

Unsurprisingly, imine C1 showed the fastest hydrolysis of this series, with $a h_{1 / 2}$ of $4.5 \mathrm{~h}$, similar to its previously studied analogue $\mathbf{A 1}$. With a moderately hydrophobic linker, as in $\mathbf{6 6}$, an approximately three times longer $h_{1 / 2}$ was measured, while the more hydrophobic tyramine linker in $\mathbf{C 5}$ led to an $\mathrm{h}_{1 / 2}$ of $150 \mathrm{~h}$ (33 times longer with respect to $\mathbf{C} \mathbf{1}$ ).

We also evaluated the kinetic effect of the concentration on three amphiphilic hexylcinnamic aldehyde derivatives, C1, C6 and C7 (Figure 6). This effect was not studied in detail for $\mathbf{C 5}$ because of its already high stability at $10 \mathrm{mM}$ and its $h_{1 / 2}$ that reached several weeks at higher concentrations.

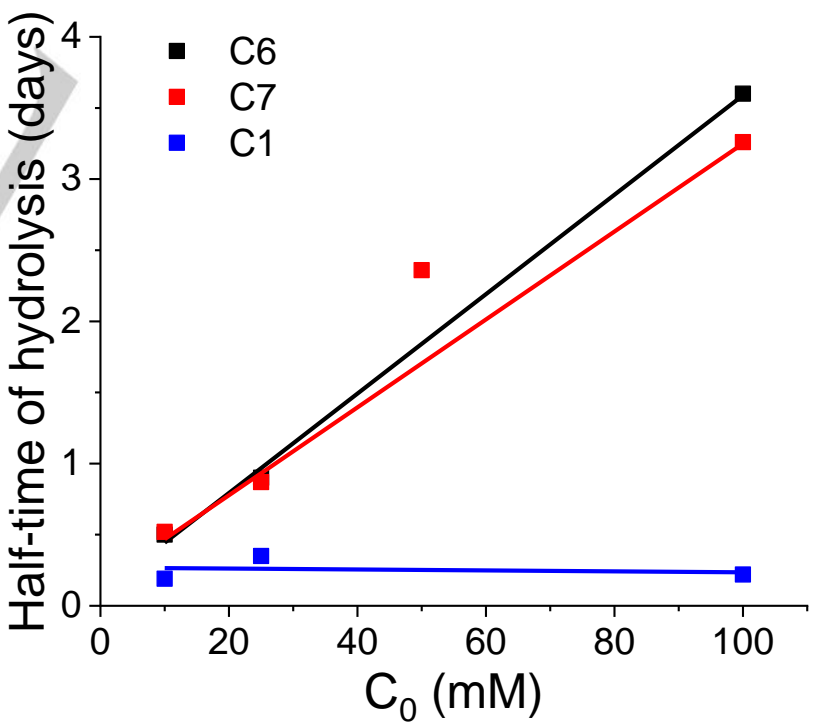

Figure 6. Evolution of the half-time of hydrolysis for compounds $\mathbf{C 1}, \mathbf{C 6}$ and C7 as a function of initial concentration at unmodified $\mathrm{pD}(10.5<\mathrm{pD}<11.3)$.

Interestingly, $\mathrm{h}_{1 / 2}$ was very fast for $\mathbf{C} \mathbf{1}$ at all concentrations, which is in agreement with poor stabilization of the imine. The more stable micellar imines $\mathbf{C 6}$ and $\mathbf{C 7}$ showed a similar and strong dependency on concentration. This result has two implications of 
practical interest: $(I)$ it appears to be possible to slow the release of volatiles by increasing the concentration of imines, and (ii) it appears to be possible to strongly accelerate the release of the aldehyde from the imine by dilution of a concentrated stock solution.

Furthermore, from these findings, one can assume that imines that are not stabilized in water will exhibit pseudo-first-order kinetics, whereas those that are stabilized within a hydrophobic environment will exhibit pseudo-zero-order kinetics. We thus tried to fit the hydrolysis plots of $\mathbf{C 1}, \mathbf{C 5}$ and $\mathbf{C 6}$ as a function of time, using equations (2) and (3) as follows:

$C_{f i t}(t)=C_{0 \text { thorder }}(t)+C_{1 \text { st order }}(t)$

Thus: $\quad C_{f i t}(t)=C_{e q}-k_{0} * t+A * e^{-k_{1} t}$

It can be seen that all the kinetic data can be fitted by this simple model (Figure S8), showing that (I) $\mathbf{C 1}$ is mainly hydrolysed with a pseudo-first-order rate, associated with a large fraction of imine monomers in solution; that (ii) $\mathbf{C 5}$ is mostly hydrolysed by a pseudo-zero-order rate, associated with a large amount of imine being stabilized in the hydrophobic micellar core and with a constant low concentration in solution related to the CMC; and that (iii) $\mathbf{C 6}$ is hydrolysed equally by the two mechanisms.

Not surprisingly, hydrolysis of a non-amphiphilic imine profragrance, such as F6 with Jeffamine ${ }^{\circledR}$ M1000 (6) as the amine and vanillin $(\mathbf{F})$ as the aldehyde, resulted in first-order kinetics with an $h_{1 / 2}$ of $1 \mathrm{~h}$, even at an initially relatively high concentration of $500 \mathrm{mM}$. Comparing the $h_{1 / 2}$ of $\mathbf{F} 6$ with that of $\mathbf{C} 6$ showed that the hydrolysis of $\mathbf{C 6}$ is slowed by about 120 times. This important difference occurs because $\mathbf{F} 6$ does not aggregate into micelles and thus does not act as a surfactant, whereas $\mathbf{C 6}$ does.

In addition to hexylcinnamic aldehyde (C), we also investigated the controlled release of citral (D) when condensed with hydrophilic amines $P E G_{11}$ amine 1, and Jeffamines ${ }^{\circledR}$ M1000 (6) and M2070 (7). Starting from an initial concentration of $10 \mathrm{mM}$, the kinetics of hydrolysis of these citral-based imines is very peculiar and unexpected. It displayed a very fast reaction rate within the first $20 \mathrm{~min}$, immediately followed by a very stable state in which the imine no longer hydrolysed (Figure 7a). As for hexylcinnamic aldehyde, the hydrolysis profiles of D6 and D7 are very similar, here reaching a final concentration of $C_{\text {eq }}=2.8 \mathrm{mM}$, while D1 remains in its imine form at a noticeably lower concentration $\left(\mathrm{C}_{\mathrm{eq}}=1.5 \mathrm{mM}\right)$. Diffusion ordered spectroscopy NMR (DOSY NMR) experiments showed that D6 is present in water solution in its micellar form $(\mathrm{Hr}=4.7 \mathrm{~nm})$ and as unimers $(\mathrm{Hr}=1.2 \mathrm{~nm})$, whereas citral $\mathbf{D}$ is present only within the micellar structures.

The rapid hydrolysis of the citral-based imine at the very beginning of the kinetic profile seems to reflect an intrinsic sensitivity of that particular imine bond to water, as expected from an aliphatic aldehyde. In addition, the partial solubility of citral in water $(0.6 \mathrm{mg} / \mathrm{mL})$ induces a higher $\mathrm{CMC}$ and probably a slower kinetic formation of the micelles when the imine is transferred to water. Thus, at early time, a large quantity of monomer is present and tends to hydrolyse. Upon micellar formation, the high stabilization of the imine becomes suddenly apparent and leads to a strong change in the slope of the hydrolysis kinetics.

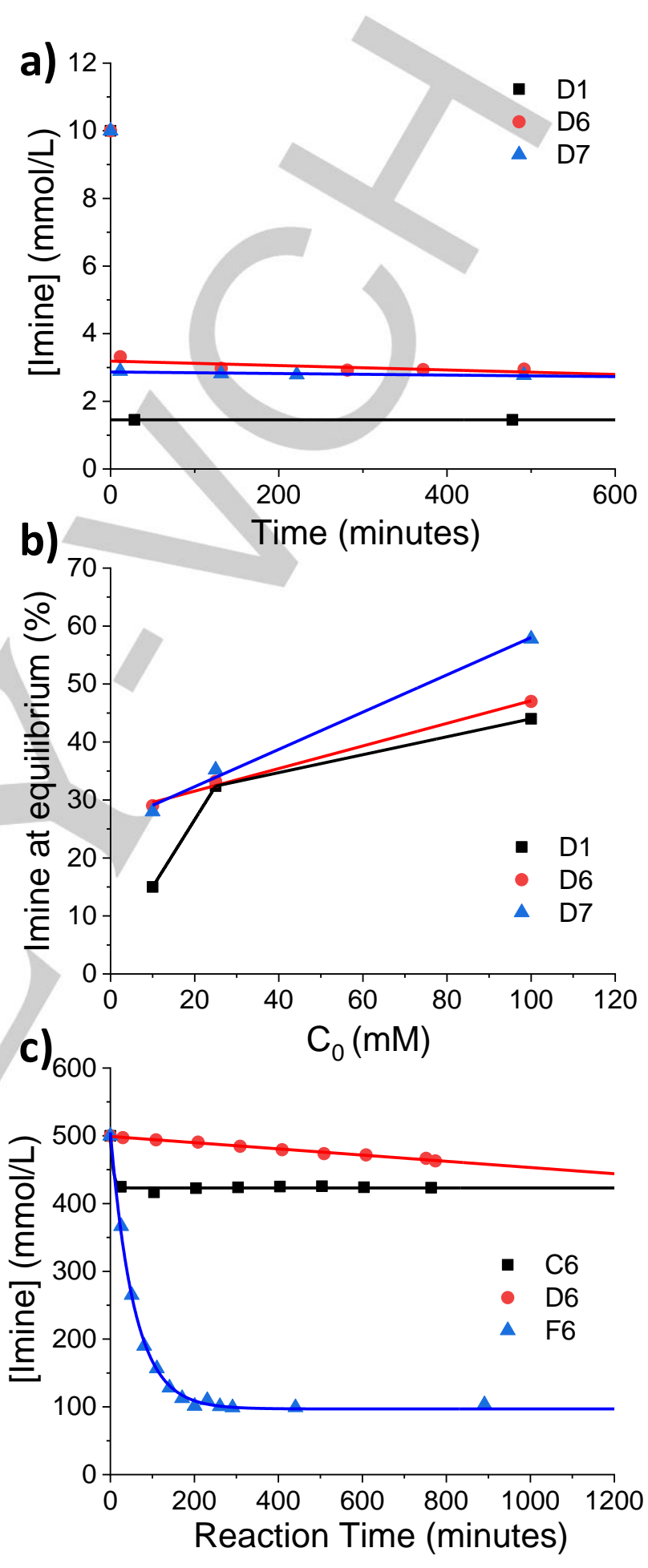

Figure 7. a) Evolution of the concentration of imines D1, D6 and D7 as a function of time in $\mathrm{D}_{2} \mathrm{O}$ for an initial concentration of $\mathrm{C}_{0}=10 \mathrm{mM}$. b) Evolution of the concentration of imines D1, D6 and D7 as a function of time, in $\mathrm{D}_{2} \mathrm{O}$ for various initial concentrations $\left(10 \mathrm{mM}<\mathrm{C}_{0}<100 \mathrm{mM}\right)$. c) Evolution of the concentration of amphiphilic imines $\mathbf{C 6}$ and D6, and non-amphiphilic imine F6 as a function of time in $\mathrm{D}_{2} \mathrm{O}$ for an initial concentration of $\mathrm{C}_{0}=500 \mathrm{mM}$. 
The percentage of condensed imine at equilibrium is also strongly dependent on the initial concentration in imine (Figure $7 \mathrm{~b}$ ), reaching about $50 \%$ to $60 \%$ of imine at equilibrium for an initial concentration of $100 \mathrm{mM}$ for the three imines D1, D6 and D7. In another experiment at an initial concentration of $500 \mathrm{mM}$ in D6, $\mathrm{C}_{\text {eq }}$ was reached within $10 \mathrm{~min}$ at $416 \mathrm{mM}(83 \%)$. This is similar behaviour to what is observed with amphiphilic $\mathbf{C 6}$, but in striking difference when compared with the non-amphiphilic vanillin derivative $\mathbf{F 6}$ (Figure 7c). This is an important observation from an application perspective because when incorporated in sealed packaging, the imine concentration should be stable over time. However, when used upon dilution, or simply by slow evaporation from the concentrated solution in open conditions, the release of the volatile will shift the imine equilibrium to full hydrolysis.

It is also important to note here that citral is known to be poorly stable in aqueous solutions due to its aliphatic aldehyde function and that its storage in stable form is a problem of industrial relevance. This aspect will be discussed further in a future paper. Finally, we turned to the possibility to further stabilize amphiphilic profragrance $\mathbf{C} \mathbf{6}$ by making use of co-surfactants. The potential beneficial effects here were twofold: $(I)$ lowering of the CMC value of the mixed system compared with that of the imine alone and (ii) investigating more realistic conditions of use as encountered in industrial formulations containing fragrances (such as body wash products and detergents). We studied the effect of additional anionic (sodium dodecyl sulphate (SDS) and Texapon ${ }^{\circledR}$ ), cationic (cetrimonium bromide) and non-ionic $\left(\mathrm{PEG}_{25}\right.$ monostearate, Triton ${ }^{\circledR}$ X-100 and Tween ${ }^{\circledR}$ 80) surfactants (see SI for detailed chemical structures (Table S2)). Their effects on the $h_{1 / 2}$ when added at a concentration of $4 \% \mathrm{w} / \mathrm{w}$ are reported in Table 4.

Table 4: Kinetic values determined for the hydrolysis of imine $\mathbf{C 6}$ in deuterated water at a concentration of $10 \mathrm{mM}$ and unmodified $\mathrm{pD}(\approx 10.5)$ in the presence of various co-surfactants $(4 \% \mathrm{w} / \mathrm{w})$.

\begin{tabular}{ccc}
\hline Surfactant type & Surfactant & $\mathrm{h}_{1 / 2}(\mathrm{~h})$ \\
\hline Non-ionic & Triton $^{\circledR} \mathrm{X}-100$ & 43.4 \\
Cationic & Cetrimonium bromide & 43.1 \\
Anionic & Texapon $^{\circledR}(+5 \% \mathrm{w} / \mathrm{w} \mathrm{NaCl})$ & 42.0 \\
Anionic & Texapon $^{\circledR}$ & 17.0 \\
Non-ionic amine & Jeffamine $^{\circledR} \mathrm{M}^{\circledR 070}$ & 16.9 \\
Non-ionic amine & Jeffamine $^{\circledR} \mathrm{M} 1000$ & 16.6 \\
No additive & No additive & 12.2 \\
Anionic & SDS & 4.9 \\
Non-ionic & $\mathrm{PEG}_{25}$ monostearate & 0.5 \\
\hline
\end{tabular}

From all the surfactants tested, when compared with the reference with no additive $\left(h_{1 / 2}=12.2 h\right)$, only SDS and $P E G_{25}$ monostearate were shown to decrease $h_{1 / 2}$ by factors of 2.5 and 24.5 , respectively. However, the SDS was shown to induce partial precipitation of the system, and hydrolysis in the presence of $\mathrm{PEG}_{25}$ monostearate was complex, with a very fast initial period followed by a strong stabilization of the system at $C_{e q}=5 \mathrm{mM}$ (Figure S9). In this case, the slow kinetics of formation of stable micelles upon mixing might be the rate-limiting step, leading to two different regimes along the course of the reaction. Conversely, one can notice that two surfactants considerably slow down the hydrolysis (by a factor of $\approx 3.5$ ), namely cationic cetrimonium bromide and non-ionic Triton ${ }^{\circledR} \mathrm{X}-100$. The corresponding plots show pseudo-zero-order kinetics associated with the hydrolysis of unimers in solution and stabilized imines in the micelles. The explanation of a lower CMC for the mixed systems imine/cosurfactant compared with that for the imine alone is in agreement with the literature. ${ }^{[72-74]}$ A second explanation would be the possible viscosity increase of the micellar core that would slow down the dynamic exchange of amphiphilic imines between the micelle and the solution. ${ }^{[75]}$ In this case, the concentration of unimers available in solution will not be constant and no longer equal to the $\mathrm{CMC}$, as limited by the exchange kinetics. This latter explanation about the influence of viscosity on the rate of hydrolysis was also supported by measuring an increase of $h_{1 / 2}$ by a factor of 2.5 for $\mathbf{C 6}$ in the presence of $\operatorname{Texapon}^{\circledR}(4 \% \mathrm{w} / \mathrm{w})$ and of $\mathrm{NaCl}(5 \% \mathrm{w} / \mathrm{w})$, as compared with Texapon ${ }^{\circledR}$ alone (Figure S10). The use of co-surfactants in real applications will be discussed further in the following paper.

\section{Discussion on the total hydrophilic-lipophilic balance (HLB(T))}

The surface activity of an amphiphilic molecule can be easily determined by measuring the surface tension at the air-water interface as a function of the concentration. The CMC, at which the surface tension reaches a constant value, indicates selfaggregation of the surfactant molecules in the bulk. To prove the surfactant properties of the new imine compounds of the present study, we measured surface tensions at the air-aqueous solution interface by using the pendant drop method.

Figure 8 presents the surface tension as a function of the concentration of imine compounds E6 and F6. The curve corresponding to (Z)-4-dodecenal derivative E6 clearly demonstrates the existence of a CMC above which the surface tension kept a constant value. The further increase of the imine compound concentration leads to micelle formation in the bulk solution. In contrast, the curve corresponding to vanillin derivative F6 does not follow the same trend, confirming the absence of micelle formation of this compound in the studied concentration range. The surface activity of the amphiphilic molecules strongly depends on the equilibrium between the hydrophobic and the hydrophilic part of the molecule. Imine E6 has a hydrophobic chain length of $12 \mathrm{C}$-atoms and a polar part consisting of 19 PEG groups. This molecule is well balanced to form spherical micelles. F6 has the same hydrophilic part of 19 PEG groups but a significantly smaller hydrophobic part with a phenolic structure. This molecule is an example of an amphiphilic molecule that cannot be considered as a surfactant because of the significant difference between the hydrophilic and hydrophobic molecular structures. 


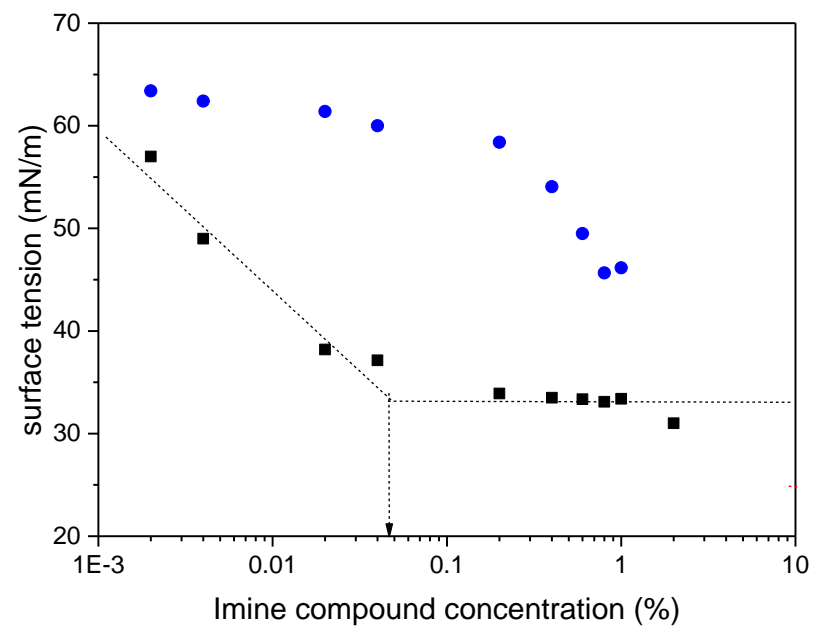

Figure 8. Surface tension at air-water interface as a function of imine compound concentration. Black squares correspond to E6 and blue circles to F6.

The hydrophilic-hydrophobic balance could be expressed by the so-called HLB number, which could be assigned to each amphiphilic molecule in order to scale its solubility in polar and nonpolar media. It is an empirical parameter that can be obtained experimentally or be estimated from the molecular structures of the surfactant molecules by using the Davies' group method. ${ }^{[76]}$ In the present study, we calculated an HLB value for each new imine by using the so-called effective chain length (ECL) model, which is a modification of Davies' method, also considering group properties of the molecules. ${ }^{[7]}$ The values are reported in Table 5 .

Table 5: Calculated HLB values $(H L B(T))$ as the sum of the corresponding values of the hydrophilic part $(Q)$, the linker $(X)$ and the hydrophobic part $(A)$ of imines according to the ECL model based on the Davies' group method.

\begin{tabular}{ccccc}
\hline Imine & HLB (Q) & HLB $(\mathbf{X})$ & HLB $(\mathbf{A})$ & HLB $_{\text {total }}$ \\
\hline C1 & 10.01 & 0 & 3.31 & 13.69 \\
C5 & 10 & 2.43 & -3.31 & 11.26 \\
C6 & 12.01 & 2.28 & -3.31 & 13.41 \\
C7 & 13.55 & 4.44 & -3.31 & 12.79 \\
D1 & 10.01 & 0 & 2.23 & 14.77 \\
D6 & 12.01 & -2.2 & -2.23 & 14.49 \\
D7 & 13.55 & 4.44 & -2.23 & 13.87 \\
E6 & 12.01 & 2.28 & -3.08 & 13.64 \\
E7 & 13.55 & 4.44 & -3.08 & 13.02 \\
F6 & 12.01 & 2.28 & 2.1 & 18.83 \\
\hline
\end{tabular}

To estimate the role of each part of the compounds according to the schematic structure in Figure 1, we considered the HLB a sum of three components: $H L B(Q)$ of the hydrophilic part, $H L B(X)$ of the linker and $H L B(A)$ of the hydrophobic part. The $H L B(T)$ of a compound is calculated by using Equation 4:

$H L B=7+H L B(Q)+H L B(X)+H L B(A)$

Wherein:

$$
\begin{gathered}
H L B(Q)=G N_{C H 3}+G N_{E O} * N_{E O}^{e f f} \\
+\sum G_{i} N_{i}(\text { other hydrophilic groups }) \\
H L B(X)=G N_{P O} * N_{P O}^{e f f}+\sum G_{j} N_{j}(\text { other lipophilic groups }) \\
H L B(A)=G N_{C H 2} * N_{C H 2}^{e f f}+\sum G_{j} N_{j}(\text { other lipophilic groups })
\end{gathered}
$$

wherein $\mathrm{GN}_{\mathrm{CH} 2}$ is the group number of a $\mathrm{CH}_{2}$ group, $\mathrm{GN}_{\mathrm{CH}}$ is the group number of a $\mathrm{CH}_{3}$ group, $G N_{E O}$ is the group number of an ethylene oxide (EO) group, $G N_{i, j}$ is the group number of a hydrophilic or lipophilic group, $G N_{P O}$ is the group number of a propylene oxide (PO) group, and wherein $\mathrm{Ni}, \mathrm{j}$ is the number of hydrophilic or lipophilic groups; $N_{C H 2}^{e f f}$ is the $\mathrm{CH}_{2}$ effective chain length defined as

$$
N_{C H 2}^{e f f}=0.965 * N_{C H 2}-0.178
$$

with $N_{C H 2}$ being the number of $\mathrm{CH}_{2}$ groups; $N_{E O}^{e f f}$ is the EO effective chain length defined as

$$
N_{E O}^{e f f}=13.45 * \ln \left(N_{E O}\right)-0.16 * N_{E O}+1.26 \text { for } N_{E O} \leq 50
$$

with $N_{E O}$ being the number of EO groups; $N_{P O}^{e f f}$ is the PO effective chain length defined as

$$
N_{P O}^{e f f}=2.057 * N_{P O}+9.06
$$

and with $N_{P O}$ being the number of $\mathrm{PO}$ groups. The values of the group numbers following the ECL method have been used as reported by Guo et al. ${ }^{[7]}$ The imine group has been considered as a tertiary amine and the group number 2.4 was used for it.

\section{Correlation of measured surface activity to the calculated HLB} values

In order to know which calculated HLB values indicate real surfactant properties, we obtained a correlation between the experimental surface tension of typical widely used and recognized non-ionic surfactants and their HLB values (Figure 9). A list of surfactants, their surface tension at a concentration of $1 \%$ $\mathrm{w} / \mathrm{w}$ and their calculated HLB values are included in Table 6. The correlation curve obtained has a sigmoidal shape with three different domains: $(I)$ a plateau at low surface tension and low HLB values; (ii) surface tension increasing with HLB value; and (iii) a plateau at high surface tension and high HLB value. The correlation between the surface tension and the HLB for the nonionic commercial surfactants (black squares) is very good. The two limits correspond to highly water soluble and highly oil soluble molecules. The surfactant molecules, which are efficient solubilizers, are positioned in the range of HLB between 10 and 18. Molecules with structures corresponding to HLB values $>18$ are highly hydrophilic and not efficient to reduce the surface tension and thus to solubilize nonpolar compounds. 


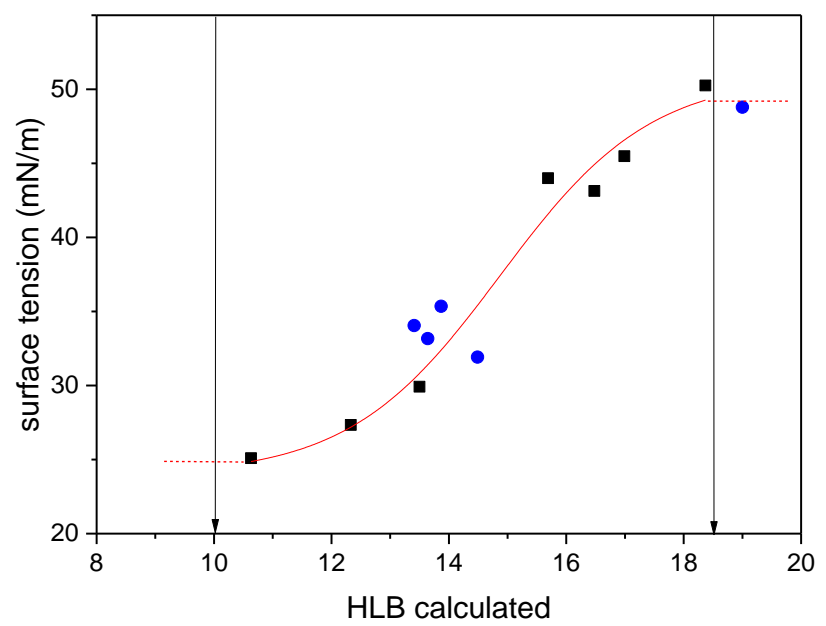

Figure 9. Correlation between the experimentally determined surface tension and calculated HLB values for a) commercial surfactants (Table 5 and black squares) and b) cleavable imines (Table 6 and blue circles).

Table 6. Experimentally determined surface tension values and calculated HLB values for commercial surfactants.

\begin{tabular}{ccc}
\hline Commercial surfactants & HLB calculated & Surface tension $(\mathrm{mN} / \mathrm{m})$ \\
\hline $\mathrm{C}_{10} \mathrm{EO}_{4}$ & 10.63 & 25.09 \\
$\mathrm{C}_{10} \mathrm{EO}_{6}$ & 12.33 & 27.34 \\
$\mathrm{C}_{10} \mathrm{EO}_{8}$ & 13.5 & 29.92 \\
PEG25 Stearate & 15.69 & 44.00 \\
$\mathrm{C}_{12} \mathrm{EO}_{23}$ & 16.48 & 43.14 \\
PEG40 Stearate & 16.99 & 45.48 \\
PEG100 Stearate & 18.37 & 50.26 \\
\hline
\end{tabular}

The data for imines C6, D6, D7, E6 and F6, were added to Figure 9 (blue circles). The surface tension values of imine surfactants (Table 7) confirm the strong surface activity of these molecules, leading to a good solubilization capacity. Vanillin derivative $\mathbf{F 6}$ has a high surface tension value, which is positioned on the surface tension plateau on Figure 9, and an HLB value exceeding the efficient surfactant limits fixed in the present study. The good correlation between the surface tension and HLB values in Figure 9 proves that the ECL method for calculation of HLB values of non-ionic surfactants is sufficiently precise to be used for the design and selection of new non-ionic surfactant-like molecules. The additive and modified method of Davies (ECL method) allows one to vary the chemical structure of the different parts, hydrophilic, lipophilic and linker, maintaining the surfactant properties of the new molecules.
Table 7. Experimentally determined surface tension values and calculated HLB values for cleavable imine surfactants.

\begin{tabular}{ccc}
\hline Cleavable imines & HLB calculated & Surface tension $(\mathrm{mN} / \mathrm{m})$ \\
\hline C6 & 13.41 & 34.05 \\
D6 & 14.49 & 31.92 \\
E6 & 13.64 & 33.17 \\
D7 & 13.87 & 35.35 \\
F6 & 19 & 48.79 \\
\hline
\end{tabular}

As a further example, we explored the influence of the size of the hydrophobic chain on the aldehyde part of imine $\mathbf{A} \mathbf{6}$ by comparing its half-life time of hydrolysis with some analogues involving alkylbenzaldehyde and alkoxybenzaldehydes that have a smaller number of carbons in their hydrophobic side chains (Figure 10).

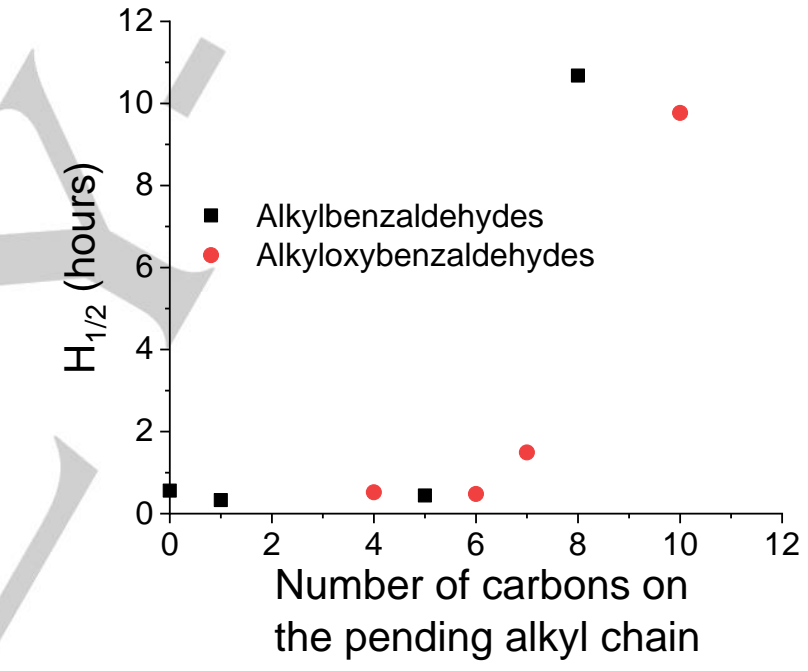

Figure 10. Influence of the hydrophobic chain length at the para position of alkyl- and alkyloxybenzaldehydes on the half-time of hydrolysis of $\mathbf{A} 6\left(\mathrm{C}_{0}=10\right.$ $\mathrm{mM}$, unmodified $\mathrm{pD}$ 10.9). Black: alkylbenzaldehydes. Red: alkyloxybenzaldehydes.

One can observe that for a number of carbons between zero and six, $\mathrm{h}_{1 / 2}$ remains constant around $0.5 \mathrm{~h}$. A noticeable slowdown of imine hydrolysis is observed only when there are more than six carbons, with a large effect for more than eight carbons, i.e. with $\mathrm{h}_{1 / 2}$ becoming larger than $10 \mathrm{~h}$. Interestingly, this fits very well with HLB values, with a large gain in $h_{1 / 2}$ for values below 15 , which correspond to the inflexion point of the surface tension curve plotted in Figure 9 (see detailed calculations for HLB values in Figure S11 and Table S1). 


\section{Conclusions}

In the present article, we have provided an overview of the hydrolytic behaviour of imine-based dynamic covalent surfactants in water with a two-fold objective: first, to stabilize volatile aldehydes into micellar cores in order to avoid their fast release by hydrolysis and evaporation, and second, to trigger hydrolysis on demand by changing some external parameters such as concentration or $\mathrm{pH}$.

During these investigations, we determined that both aromatic and aliphatic imine bonds can indeed be strongly stabilized in pure water, provided the imine surfactants form micelles. This phenomenon can be predicted by calculating HLB values, which provides a first guideline for designing such amphiphilic systems. Further, the presence of a hydrophobic linker between the imine bonds and the hydrophilic tails of the unimers reinforce their stability against hydrolysis (here up to 30 times). Beyond these structural aspects, we found that concentrations effects can also be extremely efficient in stabilizing or destabilizing imine bonds when crossing the phase diagram from unimers to micelles and vice versa, revealing strong non-linear effects. Therefore, dilution effects constitute an efficient trigger to boost the release of the entrapped volatiles. Responsiveness of such systems can also be supported by $\mathrm{pH}$ variations, with a half-time of hydrolysis varying by more than 5 orders of magnitude between $\mathrm{pH} 5$ and 13 .

Interestingly, the hydrolysis rates switch from purely first-order kinetics when imines are not stabilized in micelles, to zero-order kinetics when self-assembled in micelles because these selfassemblies play the role of a reservoir into which the imine bonds are fully protected from water. This reservoir effect can also be improved by the use of non-hydrolysable co-surfactants, which can decrease the CMC of the mixed system, and therefore decrease the concentration of free imine unimers in water solution. Overall, both the stabilization and destabilization effects highlighted in the present paper offer particular insight into the implementation of our approach to the controlled release of fragrances in a realistic application context, ${ }^{[78]}$ and this is what we describe in the paper that immediately follows.

\section{Experimental Section}

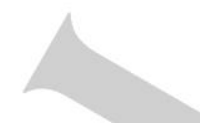

Sample preparation The syntheses of the amines and aldehydes are described in our previous work ${ }^{[25]}$ and in the SI. Imine condensation between amines and aldehydes were performed in solutions of deuterated solvents at room temperature. The molecular compositions of the systems were determined by ${ }^{1} \mathrm{H}$ NMR (Bruker advance 400 spectrometer at $400 \mathrm{MHz}$ ), integrating the imine resonance signals comparatively to those of the aldehydes. The spectra were internally referenced to the residual proton solvent signal of $\mathrm{D}_{2} \mathrm{O}(4.79 \mathrm{ppm})$.

Diffusion ordered spectroscopy NMR (DOSY NMR). ${ }^{1} \mathrm{H}$ NMR spectra were recorded on a Bruker Avance 500 spectrometer at $500 \mathrm{MHz}$ from the NMR service of Institut de Chimie de Strasbourg. The spectra were internally referenced to the residual proton solvent signal. Residual solvent peaks were taken as reference $\left(\mathrm{D}_{2} \mathrm{O}: 4.79 \mathrm{ppm}\right)$. The NMR probe is an Inverse Proton
$X$ equipped with a gradient $Z$ bobbin, able to generate pulse field gradients of 70 Gauss $\mathrm{cm}^{-1}$ with a power amplifier of $10 \mathrm{~A}$.

Surface tension measurements. Surface tension measurements were performed with a Kruss DSA 10 MK2 Drop Shape Analysis System and pendant drop geometry. For this purpose, a liquid drop was formed on the tip of a vertical needle suspended in air phase. The shape of the drop reflects the equilibrium between the surface tension and the gravity. Surface tension was calculated from the image of the pendant drop using the drop shape analysis software.

\section{Acknowledgements}

E.L. thanks Firmenich SA for a doctoral fellowship.

Keywords: amphiphiles / controlled release / dynamic covalent chemistry / imines / micelles / self-assembly

[1] N. Giuseppone, Acc. Chem. Res. 2012, 45, 2178-2188.

[2] J.-M. Lehn, Chem. Eur. J. 1999, 5, 2455-2463.

[3] P. T. Corbett, J. Leclaire, L. Vial, K. R. West, J.-L. Wietor, J. K. M. Sanders, S. Otto, Chem. Rev. 2006, 106, 3652-3711.

[4] M. C. Misuraca, E. Moulin, Y. Ruff, N. Giuseppone, New J. Chem. 2014, 38, 3336-3349.

[5] F. Schleef, U. Lüning, Eur. J. Org. Chem. 2011, 2062-2065.

[6] O. Storm, U. Lüning, Chem. Eur. J. 2002, 8, 793-798.

[7] A. Herrmann, Chem. Soc. Rev. 2014, 43, 1899-1933.

[8] A. M. Escalante, R. L. E. Furlan, in Dynamic Combinatorial Chemistry (Eds: J. N. H. Reek, S. Otto), Wiley-VCH, Weinheim, 2010, pp. 49-90.

[9] L. I. James, J. E. Beaver, N. W. Rice, M. L. Waters, J. Am. Chem Soc. 2013, 135, 6450-6455.

[10] P. Frei, R. Hevey, B. Ernst, Chem. Eur. J. 2019, 25, 60-73.

[11] M. Mondal, A. K. H. Hirsch, Chem. Soc. Rev. 2015, 44, 2455-2488.

[12] P. Dydio, P. R. Breuil, J. N. H. Reek, Isr. J. Chem. 2013, 53, 61-74.

[13] F. Schaufelberger, O. Ramström, Chem. Eur. J. 2015, 21, 1273512740.

[14] E. Moulin, G. Cormos, N. Giuseppone, Chem. Soc. Rev. 2012, 41, 1031-1049.

[15] M. Barboiu, Chem. Commun. 2010, 46, 7466-7476.

[16] Y. Zhang, Y.-M. Legrand, A. van der Lee, M. Barboiu, Eur. J. Org. Chem. 2016, 1825-1828.

[17] N. Giuseppone, J.-M. Lehn, Chem. Eur. J. 2006, 12, 1715-1722.

[18] J. M. A. Carnall, C. A. Waudby, A. M. Belenguer, M. C. A. Stuart, J. J.-P. Peyralans, S. Otto, Science 2010, 327, 1502-1506.

[19] N. Giuseppone, J.-M. Lehn, Angew. Chem. Int. Ed. 2006, 45, 46194624; Angew. Chem. 2006, 118, 4735-4740.

[20] A. Herrmann, N. Giuseppone, J.-M. Lehn, Chem. Eur. J. 2009, 15, 117-124.

[21] Y. Zhang, M. Barboiu, ACS Omega 2018, 3, 329-333.

[22] L. Tauk, A. P. Schröder, G. Decher, N. Giuseppone, Nat. Chem. 2009, 1, 649-656.

[23] N. Giuseppone, G. Fuks, J.-M. Lehn, Chem. Eur. J. 2006, 12, 1723- 
1735.

C. Godoy-Alcántar, A. K. Yatsimirsky, J.-M. Lehn, J. Phys. Org. Chem. 2005, 18, 979-985.

[25] A. M. Valdivielso, F. Puig-Castellví, J. Atcher, J. Solà, R. Tauler, I. Alfonso, Chem. Eur. J. 2017, 23, 10789-10799.

[26] N. Giuseppone, J.-M. Lehn, J. Am. Chem. Soc. 2004, 126, 11448 11449.

[27] N. Giuseppone, J.-L. Schmitt, J.-M. Lehn, J. Am. Chem. Soc. 2006, 128, 16748-16763.

[28] N. Giuseppone, J.-L. Schmitt, L. Allouche, J.-M. Lehn, Angew. Chem. Int. Ed. 2008, 47, 2235-2239; Angew. Chem. 2008, 120, 2267-2271.

[29] A. Herrmann, Chem. Eur. J. 2012, 18, 8568-8577.

[30] Y. Jin, C. Yu, R. J. Denman, W. Zhang, Chem. Soc. Rev. 2013, 42, 6634-6654.

[31] P. Chakma, D. Konkolewicz, Angew. Chem. Int. Ed. 2019, 58, 9682-9695; Angew. Chem. 2019, 131, 9784-9797.

[32] S. P. Black, J. K. M. Sanders, A. R. Stefankiewicz, Chem. Soc. Rev. 2014, 43, 1861-1872.

[33] R. Larsson, Z. Pei, O. Ramström, Angew. Chem. Int. Ed. 2004, 43 3716-3718; Angew. Chem. 2004, 116, 3802-3804.

[34] B. T. Worrell, S. Mavila, C. Wang, T. M. Kontour, C.-H. Lim, M. K. McBride, C. B. Musgrave, R. Shoemaker, C. N. Bowman, Polym. Chem. 2018, 9, 4523-4534.

[35] P. Reutenauer, E. Buhler, P. J. Boul, S. J. Candau, J.-M. Lehn, Chem. Eur. J. 2009, 15, 1893-1900.

[36] A. Karalius, Y. Zhang, O. Kravchenko, U. Elofsson, Z. Szabó, M. Yan, O. Ramström, Angew. Chem. Int. Ed. 2020, 59, 3434-3438; Angew. Chem. 2020, 132, 3462-3466.

[37] Y. Ruff, V. Garavini, N. Giuseppone, J. Am. Chem. Soc. 2014, 136 6333-6339.

[38] R.-C. Brachvogel, M. von Delius, Eur. J. Org. Chem. 2016, 3662 3670.

[39] G. Godin, B. Levrand, A. Trachsel, J.-M. Lehn, A. Herrmann, Chem. Commun. 2010, 46, 3125-3127.

[40] B. Buchs, G. Godin, A. Trachsel, J.-Y. de Saint Laumer, J.-M. Lehn, A. Herrmann, Eur. J. Org. Chem. 2011, 681-695.

[41] M. Demetriades, I. K. H. Leung, R. Chowdhury, M. C. Chan, M. A. McDonough, K. K. Yeoh, Y.-M. Tian, T. D. W. Claridge, P. J. Ratcliffe, E. C. Y. Woon, C. J. Schofield, Angew. Chem. Int. Ed. 2012, 51, 6672-6675; Angew. Chem. 2012, 124, 6776-6779.

[42] M. Röttger, T. Domenech, R. van der Weegen, A. Breuillac, R. Nicolaÿ, L. Leibler, Science 2017, 356, 62-65.

[43] N. Giuseppone, J.-L. Schmitt, E. Schwartz, J.-M. Lehn, J. Am. Chem. Soc. 2005, 127, 5528-5539.

[44] M. Ciaccia, S. Di Stefano, Org. Biomol. Chem. 2015, 13, 646-654.

[45] K. Meguellati, A. Fallah-Araghi, J.-C. Baret, A. El Harrak, T. Mangeat, C. M. Marques, A. D. Griffiths, S. Ladame, Chem. Commun. 2013, 49, 11332-11334.

[46] N. Jouault, R. Nguyen, M. Rawiso, N. Giuseppone, E. Buhler, Soft Matter 2011, 7, 4787-4800.

[47] K. Kurihara, M. Tamura, K. Shohda, T. Toyota, K. Suzuki, T. Sugawara, Nat. Chem. 2011, 3, 775-781.

[48] R. Nguyen, L. Allouche, E. Buhler, N. Giuseppone, Angew. Chem.
Int. Ed. 2009, 48, 1093-1096; Angew. Chem. 2009, 121, 1113-

1116.

[49] R. Nguyen, N. Jouault, S. Zanirati, M. Rawiso, L. Allouche, E. Buhler, N. Giuseppone, Chem. Eur. J. 2018, 24, 17125-17137.

[50] P. L. Luisi, Naturwissenschaften 2003, 90, 49-59.

[51] Y. Kang, K. Liu, X. Zhang, Langmuir 2014, 30, 5989-6001.

[52] Y. Kang, X. Tang, Z. Cai, X. Zhang, Adv. Funct. Mater. 2016, 26, 8920-8931.

[53] C. B. Minkenberg, L. Florusse, R. Eelkema, G. J. M. Koper, J. H. van Esch, J. Am. Chem. Soc. 2009, 131, 11274-11275.

[54] R. Nguyen, E. Buhler, N. Giuseppone, Macromolecules 2009, 42, 5913-5915.

[55] R. Nguyen, N. Jouault, S. Zanirati, M. Rawiso, L. Allouche, G. Fuks, E. Buhler, N. Giuseppone, Soft Matter 2014, 10, 3926-3937.

[56] C. Wang, G. Wang, Z. Wang, X. Zhang, Chem. Eur. J. 2011, 17, 3322-3325.

[57] G. Wang, C. Wang, Z. Wang, X. Zhang, Langmuir 2011, 27, 1237512380.

[58] Y. Liu, K. Liu, M. Zhao, S. Wang, Z. Zhou, Y. Shen, L. Jiang, React. Funct. Polym. 2018, 132, 138-144.

[59] A. Tehrani-Bagha, K. Holmberg, Curr. Opin. Colloid Interface Sci. 2007, 12, 81-91.

[60] D. Shukla, V. K. Tyagi, Tenside, Surfactants, Deterg. 2010, 47, 712.

[61] D. Lundberg, K. Holmberg, M. Stjerndahl, Encycl. Surf. Colloid Sci. 2016, 2, 1231-1249.

[62] A. Herrmann, Angew. Chem. Int. Ed. 2007, 46, 5836-5863; Angew. Chem. 2007, 119, 5938-5967.

[63] A. Herrmann, Photochem. Photobiol. Sci. 2012, 11, 446-459.

[64] A. Herrmann, Chimia 2017, 71, 414-419.

[65] H. Kamogawa, H. Mukai, Y. Nakajima, M. Nanasawa, J. Polym. Sci. Polym. Chem. Ed. 1982, 20, 3121-3129.

[66] T. Tree-udom, S. P. Wanichwecharungruang, J. Seemork, S. Arayachukeat, Carbohydr. Polym. 2011, 86, 1602-1609.

[67] D. Hua, J. Jiang, L. Kuang, J. Jiang, W. Zheng, H. Liang, Macromolecules 2011, 44, 1298-1302.

[68] L. Marin, B. Simionescu, M. Barboiu, Chem. Commun. 2012, 48, 8778-8780.

[69] L. Marin, S. Moraru, M.-C. Popescu, A. Nicolescu, C. Zgardan, B. C. Simionescu, M. Barboiu, Chem. Eur. J. 2014, 20, 4814-4821.

[70] A. K. Covington, M. Paabo, R. A. Robinson, R. G. Bates, Anal. Chem. 1968, 40, 700-706.

[71] A. C. Dash, B. Dash, S. Praharaj, J. Chem. Soc. Dalton Trans. 1981, 2063-2069.

[72] X. Y. Hua, M. J. Rosen, J. Colloid Interface Sci. 1982, 87, 469-477.

[73] M. J. Rosen, in Phenomena in Mixed Surfactant Systems (Ed.: J. F. Scamehorn), ACS Symposium Series 311, American Chemical Society, Washington DC, 1986, pp. 144-162..

[74] M. J. Rosen, Langmuir 1991, 7, 885-888.

[75] G. S. Kwon, M. L. Forrest (Wisconsin ALumni Research Foundation), WO 2006/110862, 2006.

[76] J. T. Davies, in Proceedings of the 2nd International Congress on Surface Activity, Butterworths, London, 1957, p. 426.

[77] X. Guo, Z. Rong, X. Ying, J. Colloid Interface Sci. 2006, 298, 441- 
450.

[78] Parts of this publication are the subject of a patent application: E. Lutz, N. Giuseppone, A. Herrmann, V. Tchakalova, D. Benczédi (Firmenich SA \& CNRS), WO 2018/134410, 2018. 


\section{Entry for the Table of Contents}

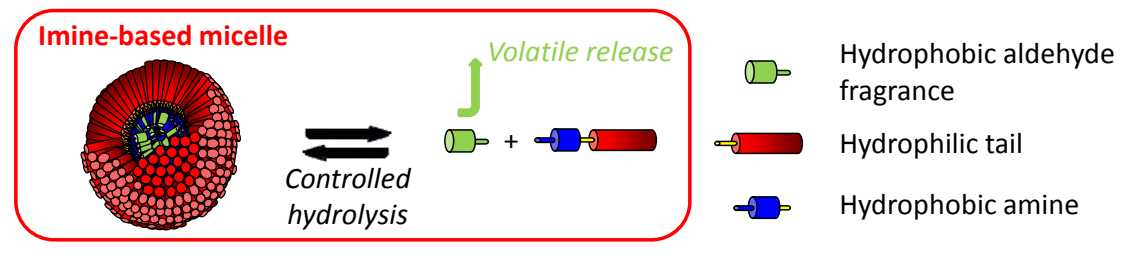

Imines are hydrolytically unstable, but can be stabilized in aqueous media by selfassembly in micellar structures. Parameters such as $\mathrm{pH}$, concentration, position of the imine function in the amphiphilic structure and relative lengths of the linked hydrophilic and hydrophobic moieties affect the stability of the imine bond and can be adapted to form stimuli-responsive micelles suitable for controlling the release of bioactive volatiles.
Eric Lutz, Emilie Moulin, Vera Tchakalova, Daniel Benczédi, Andreas Herrmann, * and Nicolas Giuseppone*

Page No. - Page No.

Design of Stimuli-Responsive Dynamic Covalent Delivery Systems for Volatile Compounds (Part 1): Controlled Hydrolysis of Micellar Amphiphilic Imines in Water 